\begin{tabular}{|c|c|c|}
\hline & $\begin{array}{l}\text { International Journal of Current Research } \\
\text { and Academic Review }\end{array}$ & \\
\hline $\begin{array}{l}\text { EXCELLENT } \\
\text { PUBLISHERS }\end{array}$ & Journal homepage: http://www.ijcrar.com & \\
\hline
\end{tabular}

doi: https://doi.org/10.20546/ijcrar.2021.901.003

\title{
Influence of Slope Gradient on Coffee Soil Fertility in Goma Woreda of Oromia Region
}

\author{
Mohammed Kedir* \\ Jimma Agricultural Research Center, P.O.Box 192, Jimma, Ethiopia \\ *Corresponding author
}

\section{Abstract}

This study was to evaluate the influence slope gradient on coffee soil fertility. Accordingly, soil samples, and field history was collected from 10 coffee farms during pinhead phase. Soil samples collected from 0-30 $\mathrm{cm}$ depth were prepared and analyzed in the laboratory following standard procedures. For data analysis, one-way ANOVA was used. The results revealed that coffee cultivations have practiced under wide range of slope gradients in study sites. Variations in slope gradients significantly influenced the coffee soil fertility. Consequently, OM, clay, CEC, available $\mathrm{P}, \mathrm{Mg}$ and $\mathrm{Na}$ generally showed a decreasing trend with increasing slope gradient, whereas sand was opposite. For sound conclusion, appropriate soil and water conservation measures, N, P, K, organic fertilizers are recommended for future work.
\end{abstract}

\section{Article Info}

Accepted: 08 December 2020

Available Online: 20 January 2021

\section{Keywords}

Slope, Soil properties, Soil test, Soil fertility.

\section{Introduction}

Soil fertility decline is resulted from loss of organic matter, macro and micronutrient depletion, soil acidity, topsoil erosion and deterioration of physical soil properties (IFPRI, 2010). In Ethiopia, the depletion rate of macronutrients N, P and K were 122,13 and $82 \mathrm{~kg} \mathrm{ha}^{-}$ ${ }^{1}$ year $^{-1}$, respectively, which estimated to be the highest in SSA (Amare et al., 2005). Ethiopia has potentially rich land resources but agricultural productivity has been below optimum yield mainly due to a range of factors including soil erosion, acidity and nutrient depletion, lack of soil fertility replenishment, nutrient mining and lack of balanced fertilization (Wondwosen and Sheleme, 2011).

Topography is one of the naturally occurring soils forming factor that affecting soil properties. Of these, slope gradient is the main element of topographic factors that determine the process of drainage; runoff and soil erosion thus affects soil physicochemical properties (Khan et al., 2013; Fanuel et al., 2016). According to Mulugeta (2015) who reported, that increased in slope gradient with increased soil loss.

In relation with slope, the average annual rate of top soil loss in the country is estimated to be 137 tons/hectare/year and it can be even higher on steep slope (IFPRI, 2010). Losing topsoil through erosion contributes a loss of inherent soil fertility levels of N, P, $\mathrm{K}$, and thus to a decline in potential crop yield. For this reason, studying the influence of slope gradient on coffee soil fertility is important to give information on nutrient status of the soil. Nevertheless, an evidence for estimation of the impact of slope gradient on coffee soil fertility has not been documented under Goma woreda 
condition. Therefore, knowing of the landscape features of coffee farms and soil management practices is important to validate the potential and limitations of the soil resources. Therefore, the objective of this study was to evaluate the influence slope gradient on coffee soil fertility Goma Woreda of Oromia region.

\section{Materials and Methods}

\section{Description of the study area}

Goma woreda is located Oromia region, south west of Ethiopia. The topography of the study area ranges from gently sloping to hilly lands with ridges and valleys in between. Altitudinal range of the woreda is between 1387-2870 m. a.s.l (IPMS, 2007).

The annual rainfall varies between $800-2000 \mathrm{~mm}$, while the mean minimum and maximum annual temperatures of the woreda vary between $7^{\circ} \mathrm{C}-12^{\circ} \mathrm{C}$ and $25^{\circ} \mathrm{C}-30^{\circ} \mathrm{C}$, respectively (ARDO, 2008).

\section{Treatments and procedures}

During collecting the soil samples, a preliminary survey was carried out to identify the slope gradient classes from smallholder coffee farms in the study sites. Accordingly, three slope gradients were identified and every farm from which soil samples was collected, had similar shade trees and soil management practices.

Thus, three slope gradient classes namely; sloping (5$10 \%)$, strongly sloping (10-15\%) and moderately steep area $(15-30 \%)$ were considered as described by (FAO, 2006) used as to evaluate impact of landscape positions on selected coffee soil properties.

Sloping treatment is replicated four times, whereas strongly sloping and moderately steep treatments are replicated three times, respectively.

Field survey, site selection, soil sampling and sampling techniques

\section{Field survey and site selection}

Gomaworeda purposively selected from coffee production potential districts of Jimma Zone. Accordingly, ten (10) smallholder coffee farmswere selected purposively based on slope gradient classes, coffee production potential and soil management practices. Primary and secondary data were collected.
Soil sample preparation and soil laboratory analysis

The soil samples were collected from the study area air dried, crushed and passed through a $2 \mathrm{~mm}$ diameter sieve for all parameters except total $\mathrm{N}$ and $\mathrm{OC}$ that passed through a $0.5 \mathrm{~mm}$ diameter selected soil physical and chemical properties were analyzed at soil laboratory of Jimma agricultural research center. Soil parameters analyzed include particle size distribution, soil $\mathrm{pH}$, organic carbon, total nitrogen, available $\mathrm{P}, \mathrm{CEC}$, exchangeable basic cations ( $\mathrm{Ca}, \mathrm{Mg}, \mathrm{Na}$ and $\mathrm{K}$ ).

Soil particle distribution was analyzed using the Bouyoucos hydrometer method (Bouyoucos, 1962). Soil $\mathrm{pH}$ was determined in a 1:2.5 soil to water ratio using a digital pH-meter (Van Reeuwijk, 1993).

Organic carbon was determined following the wet digestion method as described by Walkley and Black (1934) while percentage organic matters of the soils were determined by multiplying the percent organic carbon value by 1.724 . Total $\mathrm{N}$ of the soil was determined by the Micro-Kjeldahl digestion, distillation and titration method (Bremner and Mulvaney, 1982). Available $\mathrm{P}$ was determined using the Bray II method by shaking the soil samples with an extracting solution of $0.03 \mathrm{M}$ ammonium fluoride in $0.01 \mathrm{M}$ hydrochloric acid as described by (Bray and Kurtz, 1945).

Exchangeable bases were extracted with $1 \mathrm{~N}$ ammonium acetate at $\mathrm{pH}$ 7. Exchangeable $\mathrm{Ca}$ and $\mathrm{Mg}$ were measured by atomic absorption spectrophotometer (AAS), while exchangeable $\mathrm{Na}$ and $\mathrm{K}$ were measured by flame photometer (Rowell, 1994). For the determination of CEC, the soil samples leached with $1 \mathrm{~N}$ ammonium acetate solution and washed with ethanol (97\%) to remove excess salt followed by leaching with sodium chloride to displace the adsorbed $\left(\mathrm{NH}_{4}^{+}\right)$.

The quantity of ammonia then was measured by distillation and taken as CEC of the soil (Chapman, 1965). The percent base saturation of the soils was calculated as the percentage of the sum of the basic exchangeable cations $(\mathrm{Ca}, \mathrm{Mg}, \mathrm{K}$ and $\mathrm{Na}$ ) to the $\mathrm{CEC}$ (Bohn et al., 2001).

\section{Statistical data analysis}

Analysis of variance (one-way ANOVA) was employed to determine the presence of significant differences between the relevant soils measured parameters. For means with significant $(\mathrm{p}<0.05)$ differences, mean 
comparison was performed using the Tukey's HSD post hoc separation. For data analysis, Statistical Package for Social Science version 16 (SPSS) was used.

\section{Results and Discussions}

\section{Soil textures}

Results showed that slope gradient had a highly significant $(p<0.01)$ influence on clay contents. It was also observed that, there is an increase in slope gradient with a decrease in clay percentage. The data showed that the minimum value of clay percentage $(30.66 \%)$ was obtained from moderately steep slope and the maximum value of clay percentage (39\%) was obtained from sloping (Table 1). The sloping had 3.5 and $7.9 \%$ higher clay than the strongly sloping and moderately steep slope, respectively. This result is similar to the findings of Amuyou and Kotingo (2015), Mulugeta (2015) and Kehali et al., (2017) who reported the same scenario on clay particles. In contrast to this finding Fanuelet al., (2016) who revealed that the lowest value was recorded from almost flat, while the highest value was observed from strongly sloping and the trend was irregular. Enrichment of clay content in sloping could be attributed to the soil particles are detached due to erosion and then carried downward; thus resulted in a continuing deposition at the lower slope positions (Kehali et al., 2017).

The analysis of variance revealed that slope gradient had a significant difference $(\mathrm{P}<0.05)$ on sand fraction. The highest value $(54.66 \%)$ had been recorded from moderately steep slope, while the lowest value (49\%) was record from sloping. With connection to this, the moderately steep slope had 0.84 and $3.6 \%$ higher sandthan the strongly sloping and sloping, respectively. This present result is in agreement with, Mulugeta (2015) and Kehali et al., (2017) who found that sand fraction increased with an increase of slope gradients. High in sand content is could be due to the small soil particles move from steep slope, while the largest soil particles remained at the upper landscape positions.

The result of analysis of variance showed a significant $(\mathrm{P}<0.05)$ variation on silt fraction. The largest value $(14.68 \%)$ was recorded from the moderately steep area and the lowest value (11.34\%) from strongly sloping area. The moderately steep area had 5 and $8 \%$ higher silt fraction than the sloping and strongly sloping area, respectively. The values of silt faction were relatively lower in comparison to sand and clay proportion of sampled soils, respectively. In addition, this result agrees with finding of Fanuel et al., (2016) reported silt content was influenced by the slope gradient classes.

\section{Soil pH}

The result of analysis of variance revealed no a significant $(\mathrm{P}>0.05)$ difference on soil $\mathrm{pH}$. However, numerical variations were observed among the slope gradients. The data showed that the minimum value of soil $\mathrm{pH}$ (5.11) was obtained from moderately steep slope and the maximum value of soil $\mathrm{pH}$ (5.49) was obtained from sloping (Table 2). The sloping had 1 and $2.4 \%$ higher soil $\mathrm{pH}$ than the strongly sloping and moderately steep slope, respectively. Besides this, there was found to be a decreasing trend with an increasing of slope gradients in numerical. This result is supported by Khan et al., (2013) who reported slope positions did not change soil $\mathrm{pH}$ but the increase in soil $\mathrm{pH}$ at the bottom slope position could be because of the accumulation of bases that were presumed to have been eroded from the top to bottom slope positions. Soil $\mathrm{pH}$ can be affected by several factors other than slope positions. Of these, the parent materials, soil textures, mineral contents, climates and the degree of weathering and translocation of basic cations in the soil might be responsible for soil acidity variations because inherent factors that affect soil $\mathrm{pH}$.On contrary aforementioned, according to Siraj et al., (2015), Mulugeta (2015) and Kehali et al., (2017) depicted that soil $\mathrm{pH}$ was significantly influenced by slope gradients.

\section{Organic matter}

Results indicated a significant $(\mathrm{p}<0.01)$ effect of slope gradients on soil organic matter (Table 2). The result also shows that there is an increase in percent of organic matter with a decrease in slope gradient. Similarly, largest value $(4.3 \%)$ was recorded from the sloping and the lowest value $(2.95 \%)$ from moderately steep area. The sloping had 7.84 and $12.6 \%$ higher OM than the strongly sloping and moderately steep slope, respectively. However, strongly sloping and moderately steep slope was not significant from each other. This result is in agreement with the findings of Amuyou and Kotingo (2015) and Mulugeta (2015) who reported that the quantity of organic matter was found to be higher on lower slope gradients in comparison to the medium and upper slope gradient classes. Khan et al., (2013) reported Excess amount of $\mathrm{OM}$ in lower slope could be explained by the soil materials, which are downward movement with runoff water from upper slope and accumulation at 
the bottom slope position. Similarly, Amuyou and Kotingo (2015) revealed high OM in bottom slope is probably associated to the effect of cultivation and geomorphologic processes that result in the transportation and deposition of soil materials.

Generally, Organic matter is expected to provide plant nutrients. Similarly, Khan et al., (2013) reported that decrease in soil organic matter content at top slope with erosion hazards could have decreased the available $\mathrm{P}$ and $\mathrm{K}$ in soil at top slope position. Therefore, the study area calls for soil conservation activity to avoid soil erosion, and soil management practices in order to enhance soil fertility for the purpose of sustainable production.

\section{Total nitrogen}

Results depicted no a significant ( $p>0.05)$ variation of slope gradients on total nitrogen. However, this result disagrees with Mulugeta (2015) and Kehali et al., (2017) who reported that total nitrogen was affected by slope gradient classes. In spite of non-significant, the distribution of $\mathrm{TN}$ followed the distribution patterns of organic matter. The relatively highest $(0.24 \%)$ and the lowest $(0.16 \%)$ contents of total nitrogen were recorded in soils of sloping and moderately steep slope areas, respectively. In addition, the sloping had 6.67 and $13.3 \%$ higher TN than the strongly sloping and moderately steep slope, respectively. The factors that cause nonsignificant in TN across coffee farms could be attributed to impact of shade trees that responsible for moderate surroundings. Similar result was obtained by Fanuel et al., (2016) who revealed that total nitrogen was not significantly varied by the landscape positions.

\section{Available phosphorus}

The result of analysis of variance revealed highly significant $(\mathrm{P}<0.01)$ difference on available phosphorus (Table 2). However, strongly sloping and moderately steep slope was non-significant. This current study implies that available phosphorus increased linearly and significantly with the decrease in slope gradient classes. Accordingly, the highest value (3.24 ppm) had been recorded from sloping, whereas the lowest value $(0.9$ $\mathrm{ppm}$ ) was recorded from moderately steep slope, respectively. Furthermore, the sloping had 28.34 and $40.69 \%$ higher phosphorus than the strongly sloping and moderately steep slope, respectively. However, Amuyou and Kotingo (2015) and Fanuel et al., (2016) reported available phosphorus trend along slope categories were not stable.

\section{Exchangeable calcium}

Results showed that the slope gradients did not affect exchangeable calcium significantly. In numerical, however, there was a decreasing trend with an increase of slope gradient classes. Similarly, relatively the lowest (3.32 meq/100 g) and highest (4.69 meq/100 g) contents of exchangeable calcium were recorded in soils of moderately steep slope and sloping areas, respectively (Table 2). The sloping had 5.9 and $11.4 \%$ higher exchangeable calcium as compared to the strongly sloping and moderately steep slope, respectively. This result is supported by the work of Fanuel et al., (2016) who reported that exchangeable calcium did not affect by slope gradient classes. Non-significant of $\mathrm{Ca}^{2+}$ through coffee farms might be explained by the low variation in soil acidity, impacts of shade trees, nature of parent materials. According to Mulugeta (2015), reported exchangeable calcium was strongly dependent on soil acidity. The highest value of exchangeable calcium was observed in sloping could be attributed to the removal soil materials from the steep slope areas through runoff, erosion, and deposition in areas having lower slope classes.

\section{Exchangeable magnesium}

Result of analysis variance (Table 2) showed that the slope gradients had a significant effect on exchangeable magnesium. On the other hand, sloping and strongly sloping was not significant from each other. This present result indicates that the exchangeable magnesium increased with decreased slope gradients. In view of that, the highest value $(1.48 \mathrm{meq} / 100 \mathrm{~g})$ had been observed from sloping, while the lowest value $(1.26 \mathrm{meq} / 100 \mathrm{~g})$ was observed from moderately steep slope, respectively. The sloping had 2 and $5.3 \%$ higher exchangeable magnesium over the strongly sloping and moderately steep slope, respectively. Similar was obtained by Amuyou and Kotingo (2015) and Kehali et al., (2017) who reported the amount of exchangeable magnesium contents were found to be higher on lower slope gradient as compared to medium slope and upper slope gradients.

The variation of exchangeable magnesium along slope gradients could be due to the variation of organic matter differences, clay particles, top soil erosion, degree of leaching and soil $\mathrm{pH}$ variation. This result indicates exchangeable magnesium was not only affected by slope gradient classes but can also be affected by aforementioned factors. This indicates that presence of organic matter and clay particles increase the magnesium 
in soil system. Moreover, Exchangeable magnesium showed their distribution pattern in slope gradient classes. This result is similar to the finding of Mulugeta (2015).

\section{Exchangeable potassium}

Result of analysis variance showed that the slope gradients had no significant $(\mathrm{P}>0.05)$ effect on exchangeable potassium in Table 2. However, numerical variations were observed among the slope gradients. This implies that the exchangeable potassium had also not a similar trend like other variables. The highest value (2.54 $\mathrm{meq} / 100 \mathrm{~g}$ ) had been observed from strongly sloping, while the lowest value $(2.07 \mathrm{meq} / 100 \mathrm{~g})$ was observed from moderately steep slope, respectively. In relation to this, the strongly sloping had 1.85 and $6.69 \%$ higher exchangeable potassium than the sloping and moderately steep slope, respectively. Kehali et al., (2017) who reported there was no significant variation among slope gradients on exchangeable potassium concentration also support this result.

A possible reason for non-significant is that, the role of shade trees can be expressed by the improving ecosystems, thus resulted in the reduction of the impact of landscape positions on soil chemical properties. According to Likassa (2014) reported the shade trees were more environmental sound as compared to chemical fertilization is added to soil. On the other hand, according to Siraj et al., (2015), Mulugeta (2015) and Fanuel et al., (2016), who, revealed that exchangeable potassium was significantly influenced by the slope gradient classes, which were opposite to the present study. Similarly, Mulugeta (2015) reported that the accumulation of exchangeable magnesium contents were relatively higher on lower slope gradient over medium slope and upper slope gradients, respectively.

\section{Exchangeable sodium}

Results indicated slope gradients had highly significant $(\mathrm{p}<0.01)$ difference on exchangeable sodium contents (Table 2). This result depicts that the quantity of exchangeable sodium levels were observed to be relatively greater on lower slope gradient followed by medium and upper slope gradients. Consequently, the highest value $(0.31 \mathrm{meq} / 100 \mathrm{~g})$ had been recorded from sloping, while the lowest value $(0.07 \mathrm{meq} / 100 \mathrm{~g})$ was recorded from moderately steep slope, respectively. Nonetheless, strongly sloping and moderately steep slope was non-significant. The sloping had 35.3 and $47 \%$ higher exchangeable sodium as compared to the strongly sloping and moderately steep slope, respectively. This result is similar to Mulugeta (2015) who reported highest sodium concentration at lower slope gradient classes. The factors, which were responsible for lower at upper position, might be associated with basic cations lost through top soil erosion, runoff, leached downward, and higher soil acidity. This investigation implies exchangeable sodium was influenced by soil acidity in coffee growing farms of study sites.

\section{Cation exchangeable capacity}

Result of analysis variance showed slope gradients had highly significant $(\mathrm{p}<0.01)$ change on cation exchangeable capacity. It was also recorded that, there is an increase in slope gradients with a decrease in CEC. Similarly, the data showed that the minimum value of CEC (16.42 meq/100g) was obtained from moderately steep slope and the maximum value of CEC (23.51 meq/100g) was obtained from sloping (Table 2). The sloping had 8.74 and $12.15 \%$ higher exchangeable CEC than the strongly sloping and moderately steep slope, respectively. However, strongly sloping and moderately steep slope was not significant from each other. The distribution of CEC in different slope gradients followed clay and organic matter distribution patterns. This investigation suggests that CEC can be governed by soil organic matter and clay percentage. The results of this study are in agreement with the findings of Mulugeta (2015) and Kehali et al., (2017), who revealed that the accumulation of CEC was found to be greater on lower slope gradients than on the medium and upper slope gradient classes.

\section{Percentage of base saturation}

Result of analysis variance showed that the slope gradients had no significant $(\mathrm{P}>0.05)$ difference on PBS. On the other hand, numerical variations were observed among the slope gradients. This result suggests that the PBS had not similar distribution patterns through slope gradient classes. Correspondingly, the data showed that the minimum value of PSB (31.69\%) was obtained from strongly sloping and the maximum value of PBS $(40.95 \%)$ was obtained from moderately steep slope (Table 2). This result disagrees with findings of Mulugeta (2015) and Siraj et al., (2015) reported that PBS was affected by slope positions.

In this study, contribution of shade trees to microclimate, soil moistures and light intensity may be responsible for 
minimizing variation in PBS among landscape positions. This result corroborates with Likassa (2014) reported shaded coffee farms better soil chemical properties than un-shaded coffee farms.

Table.1 Mean soil textures as influenced by different slope gradients

\begin{tabular}{|l|l|l|l|}
\hline Slope classes & Sand $(\%)$ & Clay $(\%)$ & Silt $(\%)$ \\
\hline S & $49 \mathrm{a}$ & $39 \mathrm{a}$ & $12 \mathrm{a}$ \\
\hline SS & $53.33 \mathrm{~b}$ & $35.33 \mathrm{~b}$ & $11.34 \mathrm{~b}$ \\
\hline MSS & $54.66 \mathrm{~b}$ & $30.66 \mathrm{c}$ & $14.68 \mathrm{a}$ \\
\hline Significance & $*$ & $* *$ & $*$ \\
\hline
\end{tabular}

Means in a column that do not share the same letter are significantly different by Tukey's HSD $(\mathrm{P}=0.05)$. Where $\mathrm{S}=$ sloping, $\mathrm{SS}=$ Strongly Sloping, MSS= moderately steep slope.

Table.2 Mean of soil chemical properties as influenced by different slope gradients

\begin{tabular}{|c|c|c|c|c|c|c|c|c|c|c|}
\hline \multirow{2}{*}{$\begin{array}{l}\text { Slope } \\
\text { classes }\end{array}$} & \multirow{2}{*}{$\begin{array}{l}\text { Soil } \\
\mathrm{pH}\end{array}$} & $\mathrm{OM}$ & TN & \multirow{2}{*}{$\begin{array}{l}\text { AvP } \\
\text { Ppm }\end{array}$} & $\mathrm{Ca}$ & $\mathrm{Mg}$ & $\mathrm{K}$ & $\mathrm{Na}$ & CEC & \multirow{2}{*}{$\begin{array}{l}\text { PBS } \\
\%\end{array}$} \\
\hline & & $\%$ & & & \multicolumn{5}{|c|}{ Meq/100g } & \\
\hline $\mathrm{S}$ & $5.49 a$ & $4.3 b$ & $0.24 a$ & $3.24 b$ & $4.69 a$ & $1.48 \mathrm{~b}$ & $2.41 \mathrm{a}$ & $0.31 b$ & $23.51 b$ & $38.34 \mathrm{a}$ \\
\hline SS & $5.34 \mathrm{a}$ & $3.46 \mathrm{a}$ & $0.20 \mathrm{a}$ & $1.61 \mathrm{a}$ & $3.98 \mathrm{a}$ & $1.40 \mathrm{ab}$ & $2.54 \mathrm{a}$ & $0.13 a$ & $18.41 \mathrm{a}$ & $31.69 \mathrm{a}$ \\
\hline MSS & $5.11 \mathrm{a}$ & $2.95 \mathrm{a}$ & $0.16 \mathrm{a}$ & $0.9 \mathrm{a}$ & $3.32 \mathrm{a}$ & $1.26 \mathrm{a}$ & $2.07 \mathrm{a}$ & $0.07 \mathrm{a}$ & $16.42 \mathrm{a}$ & $40.95 \mathrm{a}$ \\
\hline $\begin{array}{l}\text { Significan } \\
\text { ce }\end{array}$ & Ns & $* *$ & Ns & $* *$ & Ns & $*$ & Ns & $* *$ & $* *$ & ns \\
\hline
\end{tabular}

Means in a column that do not share the same letter are significantly different by Tukey's HSD. Where S= sloping, SS= Strongly Sloping, MSS= moderately steep slope; AvP= Available Phosphorus; *= significant; ns= non-significant

Summary and conclusion are as follows:

Result revealed generally selected soil physic-chemical properties significantly influenced by slope gradient classes. Similarly, organic matter, available $\mathrm{P}, \mathrm{Mg}, \mathrm{Na}$, CEC and clay particles were higher at sloping comparable with strongly sloping and moderately steep slope. Nevertheless, sand particle was higher at moderately steep slope as compared to sloping and strongly sloping. Furthermore, result concluded with exceptional sand particle, slope gradient increased with a decreased of most soil parameters.

\section{References}

Amare Haileslassie, Priess, J., Veldkamp, E., Teketay, D., Lesschen, J.P., 2005. Assessment of soil nutrient depletion and its spatial variability on smallholders' mixed farming systems in Ethiopia using partial versus full nutrient balances. Agriculture, Ecosystem and Environment, 108(1): 1-16.

Amuyou, U. A. and Kotingo, K. E., 2015.Toposequence analysis of soil properties of an agricultural field in the Obudu Mountain slopes, cross river stateNigeria. European journal of physical and agricultural sciences, 3(1).

ARDO. 2008. Annual Report of Agriculture and Rural Development Office of Gommaworeda, for year 2007/2008, Agaro, Gomma

Bohn, H.L., McNeal, B.L. and O'Connor, G.A., 2001. Soil Chemistry. 3rd Edition. John Wiley and Sons, Inc., USA.

Bouyoucos, G.J., 1962. Hydrometer method improvement for making particle size analysis of soils.Agronomy, 54(5): 179-186.

Bray R.H. and Kurtz, L.T., 1945. Determination of total, organic, and available forms of phosphorus in soils. Soil science, 59(1): 39-46. 
Bremner, J.M. and Mulvaney, C.S., 1982. Nitrogen total. Methods of soil analysis. Part 2.Chemical and microbiological properties, (methodsofsoilan2), pp. 595-624.

Chapman, H.D., 1965. Cation-exchange capacity 1. Methods of soil analysis.Part 2.Chemical and microbiological properties, (methods of soilanb), pp.891-901.

FanuelLaekemariam, KibebewKibret, TekalignMamo, Erik Karltun and Heluf Gebrekidan. 2016. Physiographic characteristics of agricultural lands and farmers' soil fertility management practices in Wolaita zone, Southern Ethiopia. Environmental Systems Research, 5(1):24.

FAO (Food and Agriculture Organization). 2006. Guidelines for Soil Description, 4th Edition. FAO, Rome, Italy.

International Food Policy Research Institute (IFPRI), 2010. Fertilizer and Soil Fertility Potential in Ethiopia. IFPRI, Washington DC, USA.

IPMS, 2007. Improving productivity and marketing success of Ethiopian farmer project Gomma pilot learning woreda diagnosis and programdesign. www.ipmsethiopia.org/content/file/document/PLS DPD/gomma.pdf.

KehaliJembere, TekalignMamo and KibebewKibret. 2017. Characteristics of agricultural landscape features and local soil fertility management practices in Northwestern Amhara, Ethiopia. Journal of Agronomy, 16(4):180-195.

Khan F, Hayat Z, Ahmad W, Ramzan M, Shah Z, Sharif M, Ahmad I.M. and Hanif M. 2013. Effect of slope position on physicochemical properties of eroded soil. Soil Environ, 32(1): 22-28.

Likassa Ebisa. 2014. Effect of dominant shade trees on coffee production in Manasibu district, west Oromia, Ethiopia. Science, Technology and Arts Research Journal, 3(3):18-22.

Mulugeta Aytenew. 2015. Effect of Slope Gradient on Selected Soil Physicochemical Properties of Dawja Watershed in Enebse Sar Midir District, Amhara National Regional State. American Journal of Scientific and Industrial Research, 6(4):74-81.

Siraj Beshir, Mulugeta Lemeneh and Endalkachew Kissi. 2015. Soil Fertility Status and Productivity Trends along a Toposequence: A Case of Gilgel Gibe Catchment in Nadda Assendabo Watershed, Southwest Ethiopia. International Journal of Environmental Protection and Policy, 3(5): 137144.

Van Reeuwijk, L.P., 1993. Procedure for Soil Analysis. 4th Edition. International Soil Reference Center Wageningen. (ISRIC) Technical Paper no. 9.The Netherlands.

Walkley, A. and Black, I.A., 1934. An examination of the Digestion method for determining soil organic matter and a proposed modification of the chromic acid titration method. Open Journal Soil Science, 37:29-38.

Wondwosen Tene and Sheleme Beyene (2011) Identification of growth limiting nutrient(s) in Alfisols: soil physico-chemical properties, Nutrient Concentration and Biomass Yield of Maize. American Journal of plant nutrient and fertilizer technology 1(1): 23-35.

\section{How to cite this article:}

Mohammed Kedir. 2021. Influence of Slope Gradient on Coffee Soil Fertility in Goma Woreda of Oromia Region. Int.J.Curr.Res.Aca.Rev. 9(01), 43-49. doi: https://doi.org/10.20546/ijcrar.2021.901.003 